Article

\title{
Correlation between Fructan Exohydrolase Activity and the Quality of Helianthus tuberosus L. Tubers
}

\author{
Tatjana Krivorotova ${ }^{1,2}$ and Jolanta Sereikaite ${ }^{1, *}$ \\ 1 Department of Chemistry and Bioengineering, Vilnius Gediminas Technical University, Vilnius LT-10223, \\ Lithuania; tatjana.krivorotova@chf.vu.lt \\ 2 Institute of Chemistry, Vilnius University, Vilnius LT-03225, Lithuania \\ * Correspondence: jolanta.sereikaite@vgtu.lt; Tel.: +370-5-2744972; Fax: +370-5-2744844
}

Received: 13 July 2018; Accepted: 11 September 2018; Published: 13 September 2018

\begin{abstract}
Jerusalem artichoke tubers have diverse applications in the food industry as well as in biotechnology. Their suitability depends mostly on the inulin content. Seasonal fluctuations of fructan exohydrolase activity responsible for inulin degradation was investigated in the tubers of three Jerusalem artichoke cultivars. The changes of fructan exohydrolase activity positively correlated with the changes of the content of total and short fructooligosaccharides. Therefore, to extract inulin with higher degree of polymerization for biotechnological purposes, the tubers of Jerusalem artichoke should be uprooted in autumn before the level of fructan exohydrolase reaches its maximum. If short fructooligosaccharides are desirable, the tubers in late autumn or spring tubers overwintered in soil are suitable.
\end{abstract}

Keywords: fructan exohydrolase activity; fructooligosaccharides; inulin; Jerusalem artichoke; seasonal fluctuations

\section{Introduction}

Jerusalem artichoke (Helianthus tuberosus L.) is a perennial plant and belongs to the same Asteraceae family as the sunflower (Helianthus annuus L.). Jerusalem artichoke is native to North America. Since 17th century it has been grown in Europe [1]. Now it is cultivated over the world and represents a low-cost biomass feedstock for biorefinery [2,3]. The plant grows fast, shows a good tolerance to frost, drought and poor soil as well as resistance to pest and diseases. Jerusalem artichoke is highly competitive and can repress the growth of other species [3,4]. The tubers of Jerusalem artichoke contain inulin as a reserve carbohydrate. They can be used as feedstock for the production of biofuels and bio-based chemicals. Stalks of Jerusalem artichoke also are usable for the production of paper pulp, biofuels, and animal feed $[3,5]$.

Inulin consists of linear $\beta(2->1)$ linked fructofuranosyl units terminated by a glucose residue through a sucrose type linkage. The (2->1) linked fructosyl residues of inulin are not hydrolyzed by human enzymes. Inulin serves as a soluble dietary fiber and the ingredient of functional food. It is also known as prebiotic and stimulates the growth of beneficial bacteria in human colon $[4,6]$. In the food industry, inulin is also used as a fat replacer and texture modifier [7]. Moreover, Jerusalem artichoke tubers and inulin are an advantageous feedstock for fructose syrup production [4,5]. An interest in fructose is gradually growing since fructose has a higher sweetener power than glucose and is suitable for patients with diabetes or obesity [8]. Therefore, Jerusalem artichoke tubers have a diverse application not only in the food industry, but also in biotechnology. Their suitability depends mostly on the inulin content [9].

Two enzymes are responsible for the synthesis of inulin in Jerusalem artichoke. According to Edelman and Jefford [10], inulin is synthesized from sucrose by sucrose:sucrose 1-fructosyltransferase 
(1-SST, EC 2.4.1.99) and fructan:fructan 1-fructosyltransferase (1-FFT, EC 2.4.1.100). 1-SST synthesizes 1-kestose by transferring fructose from another sucrose molecule. 1-FFT elongates fructose chain and transfers fructose from another 1-kestose molecule as the preferential donor. The breakdown of inulin is catalyzed by 1 -fructan exohydrolase (1-FEH). The enzyme hydrolyzes $\beta-2,1$-linkage of terminal fructosyl residue of inulin [11]. Most plant fructan exohydrolases do not convert sucrose to fructose and glucose [11], and they are classified as EC 3.2.1.153 [12].

The extensive research on the accumulation of inulin and other carbohydrates in the tubers of Jerusalem artichoke and their content depending on cultivars, harvest time, cultivation, and storage conditions has been performed [13-20]. However, a little is known about the changes of the activity of enzymes catalyzing the synthesis and degradation of inulin in tubers. To the best of our knowledge, there is only the publication of Marx and coauthors [21], in which the changes of fructan exohydrolase activity in the tubers of Jerusalem artichoke cultivar Bianca grown in the Botanic garden of the University of Zurich are presented. One of the reasons could be that the assay for FEH (fructan exohydrolase) activity determination requires expensive and not always accessible HPLC equipment [12]. Previously, we showed that the enzymatic method based on the reactions catalyzed by hexokinase, phosphoglucose isomerase, and glucose-6-phosphate dehydrogenase is suitable for FEH activity determination in plant extracts. This method is suitable for routine analysis and is immune against the interference of various compounds from plant extract [22].

Here, we present the investigation of FEH activity changes in the tubers of three Jerusalem artichoke cultivars and the relationship with the changes of carbohydrate content determining their further application in biotechnology and the food industry.

\section{Materials and Methods}

\subsection{Plant Materials}

Three cultivars of Helianthus tuberosus L., i.e., Rubik, Albik and Sauliai were grown in South Lithuania. Sauliai is a cultivar originated from Lithuania and both Rubik and Albik are from Poland. The tubers were uprooted at the end of every month from March until November (1st year) and from April until November (2nd year). The average air temperature from March until November was equal to $1.6,5.5,13.3,15.0,19.6,16.5,13.1,6.9$ and $4.5^{\circ} \mathrm{C}$, respectively, and was similar to the standard climate normal for the period of 1981-2010 years. The average air temperature during winter was approximately equal to $0{ }^{\circ} \mathrm{C}$. For the storage, tubers were peeled and cut in small pieces (about $0.3 \mathrm{~cm}$ of thickness) and frozen. Then, they were homogenized using a Bosh blender and finally put into plastic bags at $-18^{\circ} \mathrm{C}$.

\subsection{Determination of Fructan Exohydrolase Activity}

FEH activity in Jerusalem artichoke tubers extract was determined as previously described [22]. Briefly, $4 \mathrm{~g}$ of homogenized frozen material was suspended in $4 \mathrm{~mL}$ of $0.1 \mathrm{M}$ Na-acetate buffer, $\mathrm{pH} 4.5$, containing $1 \mathrm{mM}$ phenylmethylsulfonyl fluoride and $5 \mathrm{mM}$ EDTA. Then, the sample was sonicated for $3 \mathrm{~min}$ at $10{ }^{\circ} \mathrm{C}$ using a Sonics Vibracell VCX 750. For the removal of undissolved material, the sample was centrifuged at $15,000 \times g$ for $10 \mathrm{~min}$ at $4{ }^{\circ} \mathrm{C}$. A reaction mixture consisting of $0.2 \mathrm{~mL}$ of supernatant and $0.8 \mathrm{~mL}$ of $3 \%$ inulin solution in $0.1 \mathrm{M} \mathrm{Na}$-acetate buffer, $\mathrm{pH} 4.5$ was incubated for $3 \mathrm{~h}$ at $30{ }^{\circ} \mathrm{C}$. To stop the reaction, the mixture was heated at $95^{\circ} \mathrm{C}$ for $5 \mathrm{~min}$. Then, liberated fructose was measured using a Megazyme kit K-FRUGL 11/05 (Megazyme International Ireland Ltd., Wicklow, Ireland) in accordance with manufacturer recommendations. One unit of enzyme activity was defined as the amount of enzyme that liberates one $\mu \mathrm{mol}$ of fructose per $1 \mathrm{~h}$ under the reaction conditions. The specific activity was defined as $\mu \mathrm{mol} \times \mathrm{h}^{-1}$ per $\mathrm{g}$ of raw plant material. Data were presented as mean \pm SD of three independent experiments. 


\subsection{Determination of Carbohydrates}

For sugar content determination, homogenized tuber material was dried at $80{ }^{\circ} \mathrm{C}$. For the extraction of sugars, $0.6 \mathrm{~g}$ of dried material was suspended in $20 \mathrm{~mL}$ of distilled water and kept in a water bath at $80 \pm 5{ }^{\circ} \mathrm{C}$ for $30 \mathrm{~min}$. Then, the extract was cooled to room temperature and diluted up to $25 \mathrm{~mL}$ with distilled water in a $25 \mathrm{~mL}$ flask. Before using for analysis, the solution was squeezed through cheesecloth. For the determination of free glucose and fructose, Megazyme kit K-FRUGL 11/05 was used in accordance with manufacturer recommendations. The content of sucrose and fructooligosaccharides (FOS) was determined using Megazyme kit K-FRUCHK 03/05. The average degree of polymerization (DP) of FOS was calculated as described by reference [20]. The content of carbohydrates was expressed as the percentage of dry matter (DM). Data were presented as mean $\pm \mathrm{SD}$ of three independent experiments.

\subsection{Determination of Fructooligosaccharides and other Carbohydrates by HPLC}

For the determination of the content of carbohydrates in the flour extracts, a Viscotek chromatographic system equipped with a refractive index detector and Prevail Carbohydrates ES column (Alltech, $250 \mathrm{~mm} \times 4.6 \mathrm{~mm}, 5 \mu \mathrm{m}$ ) was used. The mixture of acetonitrile/water $(70 / 30, v / v)$ was used as a mobile phase at a flow rate of $1.0 \mathrm{~mL} / \mathrm{min}$ and $30^{\circ} \mathrm{C}$. Prior to injection, the solution of extract $(12 \mathrm{mg} / \mathrm{mL})$ was diluted with a mobile phase $(3 / 2, v / v)$ and filtered through a $0.2 \mu \mathrm{m}$ filter. Glucose, fructose, and sucrose from Sigma-Aldrich, and 1-kestose $\left(\mathrm{GF}_{2}\right)$, nystose $\left(\mathrm{GF}_{3}\right)$, and $1^{\mathrm{F}}$-fructofuranosyl nystose $\left(\mathrm{GF}_{4}\right)$ from Wako (Japan) were applied as standards. The amount of fructose, glucose, sucrose, $\mathrm{GF}_{2}$ (kestose), $\mathrm{GF}_{3}$, and $\mathrm{GF}_{4}$ (fructofuranosyl nystose) in the extracts $(\%, w / w)$ were calculated using standard curves. For their construction, known concentrations of each carbohydrate were used. A typical chromatogram is presented in Supplemental Figure S1.

\section{Results and Discussion}

The survey of fructan exohydrolase activity was performed over two years. The tubers were uprooted at the end of every month from March until November (1st year). Autumn tubers were left to overwinter in soil, and once again, tubers were uprooted from April until November (2nd year). For the survey, three cultivars of Jerusalem artichoke, i.e., Sauliai, Rubik, and Albik were cultivated. As can be seen from Figure 1, the highest enzymatic activity was observed in the autumn tubers (in October and November) and in the spring tubers (in March and April).

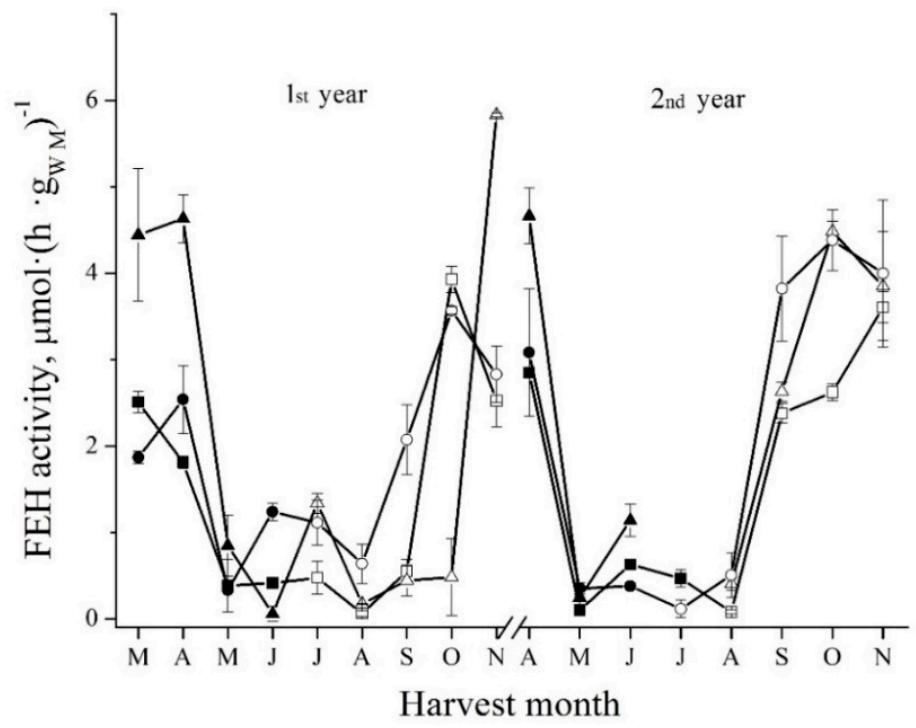

Figure 1. Seasonal fluctuations of FEH activity in the tubers of Sauliai $(\bullet, \bigcirc)$, Albik $(\boldsymbol{\Lambda}, \Delta)$ and Rubik

$(\mathbf{\square}, \square)$; spring tubers:

$\bullet, \mathbf{\Lambda}, \mathbf{\square}$; summer and autumn tubers: $\bigcirc, \Delta, \square$. 
The maximum enzymatic activity was similar in every spring. Moreover, it was also similar to the maximum of enzymatic activity in autumn. It follows that FEH activity remained at the high level in tubers overwintering in soil. The profile of FEH activity changes (Figure 1) is also similar to the one of the changes of FOS content in tubers (Figure 2A). However, it is completely different from the profile of the changes of DP of FOS (Figure 2B). It can be seen from Figures 1 and 2 that, first, the DP of FOS reaches its maximum. Then, approximately one month later, the content of FOS becomes the highest. Finally, approximately one more month later, FEH activity reaches its maximum level. At the same time, the content of FOS shows the tendency to decrease to some extent. Moreover, the DP of FOS also decreases. Marx and coauthors [21] also found that FEH activity increased in the onset of dormancy in autumn. However, our data on FEH activity during sprouting (in May) are opposite to previously published data. Marx and coauthors found that FEH activity gradually increased during sprouting. Here, as can be seen from Figure 1, the level of FEH activity, on the contrary, decreased sharply by approximately 5-fold at the end of May, as compared with the level of enzymatic activity at the end of April. It was confirmed by measuring FEH activity changes for three cultivars of Jerusalem artichoke.
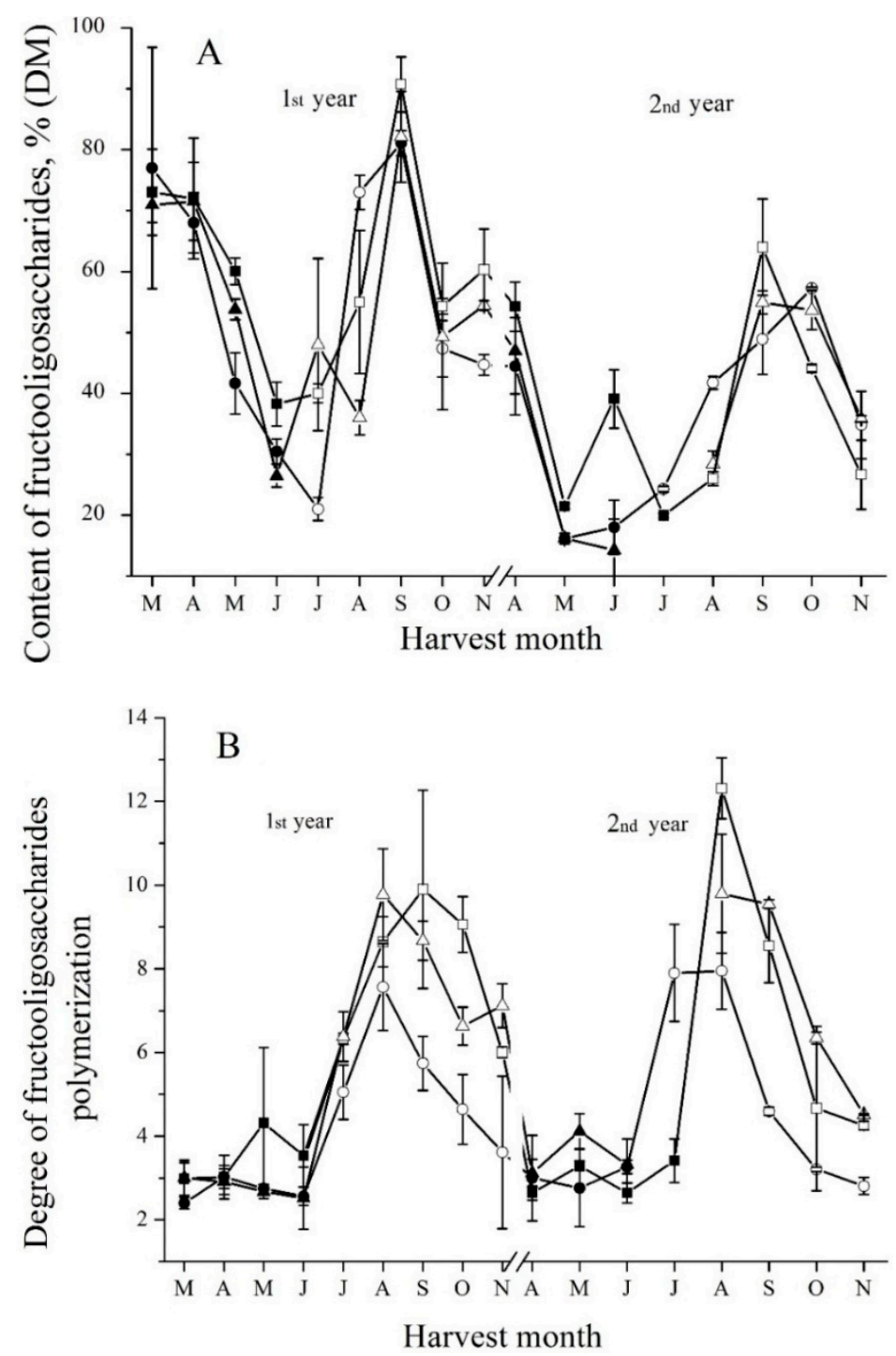

Figure 2. Seasonal fluctuations of fructooligosaccharides content (A) and degree of polymerization (B) in the tubers of Sauliai $(\bullet, \bigcirc)$, Albik $(\boldsymbol{\Lambda}, \Delta)$, and Rubik $(\mathbf{\square}, \square)$; spring tubers: $\bullet, \mathbf{\Lambda}, \mathbf{\square}$; summer and autumn tubers: $\bigcirc, \Delta, \square$. 
In spite of high content of FOS in spring tubers overwintered in soil, the DP of FOS is low (Figure 2B). However, FEH activity is high. The analysis of short FOS by HPLC revealed that the profile of the changes of content of ketose, nystose, and $\mathrm{GF}_{4}$ is very similar to the one of $\mathrm{FEH}$ activity changes (Supplemental Figure S2). Therefore, even at low DP of FOS, the level of FEH activity remains high to catalyze the hydrolysis of short FOS. It reduces by decreasing the content of short FOS. In developing tubers, on the contrary, the content of short FOS increases. It is related to fructose chain prolongation and inulin synthesis. Later, in autumn tubers, the content of short FOS also increases. In that case, it is most likely related to the high FEH activity and the decrease of the DP of FOS.

For sucrose content changes, a similar profile to the one of short FOS was found by two independent methods, i.e., enzymatic (Figure 3) and HPLC (Supplemental Figure S3). It is explainable because a glucose residue through a sucrose-type linkage terminates a fructose chain in the inulin molecule. Sucrose molecules are released by degrading short FOS molecules which are further hydrolyzed to glucose and fructose. However, it seems that plant acid invertases (EC 3.2.1.26) are responsible for the decrease of sucrose content $[23,24]$ because known plant FEH are unable to degrade sucrose [11]. However, it is difficult to establish the relationship between the sucrose content and the activity of acid invertase in Jerusalem artichoke tubers. There are no data about the seasonal changes of invertase activity in the plant. Some data on the changes of invertase activity were published only for Jerusalem artichoke under salinity and drought treatments [25].

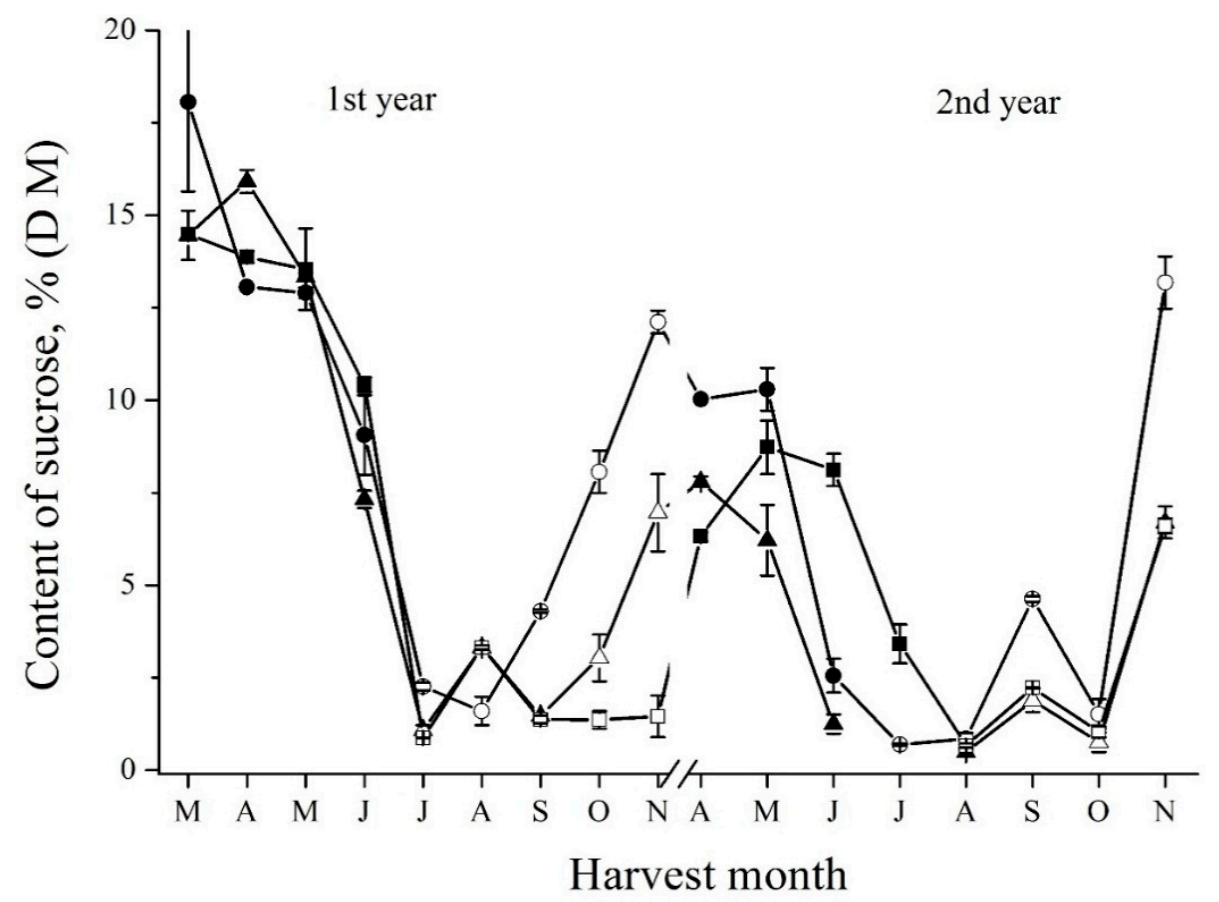

Figure 3. Seasonal fluctuations of sucrose determined by enzymatic method in the tubers of Sauliai $(\bullet, \bigcirc)$, Albik $(\boldsymbol{\Lambda}, \Delta)$, and Rubik $(\boldsymbol{\square}, \square)$; spring tubers: $\bullet, \mathbf{\Lambda}, \mathbf{\square}$; summer and autumn tubers: $\bigcirc, \Delta, \square$.

The changes of glucose content (Figure 4 and Supplemental Figure S4) inversely correlated with the changes of short FOS (Supplemental Figure S2) and sucrose (Figure 3) content. In senescent spring tubers, an increasing amount of glucose was found due to the hydrolysis of sucrose. In new developing tubers, the content of glucose also was high and drastically decreased in autumn due to short FOS and inulin synthesis. For free fructose, on the contrary, a sharp peak was observed in May during sprouting (Figure 5 and Supplemental Figure S5). Marx and coauthors [21] also observed the increase of free fructose in sprouting. After the sharp increase, the level of fructose begins to decrease. In autumn tubers, free fructose level remains low because it is metabolized for inulin biosynthesis [26]. 


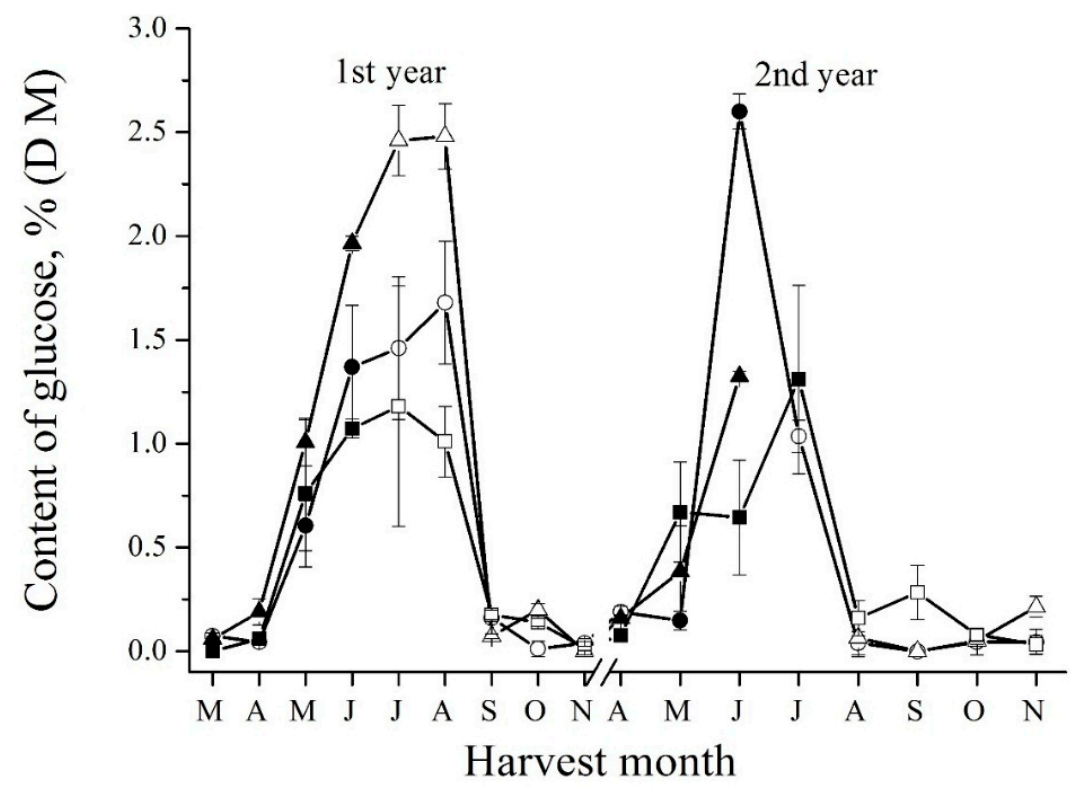

Figure 4. Seasonal fluctuations of glucose determined by enzymatic method in the tubers of Sauliai $(\bullet, \bigcirc)$, Albik $(\boldsymbol{\Lambda}, \Delta)$, and Rubik $(\boldsymbol{\square}, \square)$; spring tubers: $\bullet, \mathbf{\Lambda}, \mathbf{\square}$; summer and autumn tubers: $\bigcirc, \Delta, \square$.

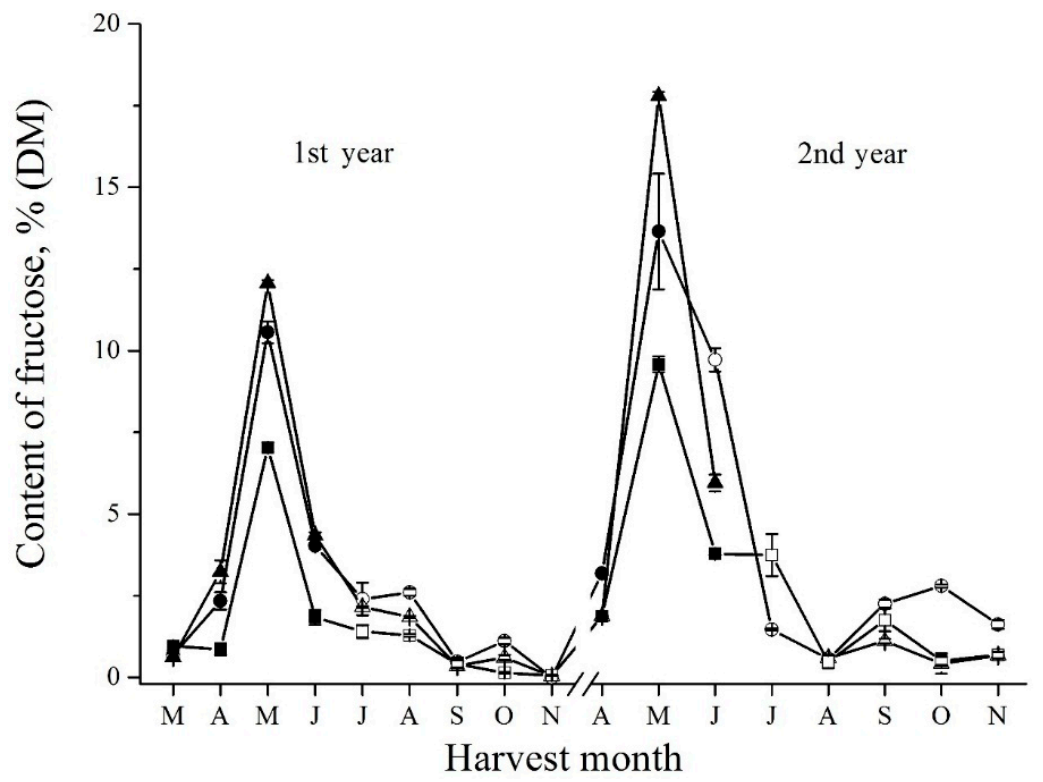

Figure 5. Seasonal fluctuations of fructose determined by enzymatic method in the tubers of Sauliai $(\bullet, \bigcirc)$, Albik $(\boldsymbol{\Lambda}, \Delta)$, and Rubik $(\mathbf{\square}, \square)$; spring tubers: $\bullet, \mathbf{\Lambda}, \mathbf{\square}$; summer and autumn tubers: $\bigcirc, \Delta, \square$.

Jerusalem artichoke is one of the most important raw materials for the industrial production of inulin and fructose [4]. To enhance the potential of the industrial crop and to increase the yield of inulin and other sugars, new Jerusalem artichoke clones have been developed [27]. Moreover, the new extraction methods of inulin have been investigated and conventional extraction techniques have been optimized [28]. The application of inulin also depends on its degree of polymerization. Physico-chemical and functional properties of inulin are related to the length of biopolymer chain. For different industrial purposes, inulin of variable DP can be used. Inulin with a lower degree of DP is more soluble and sweeter than the fractions with higher DP. Moreover, the degree of polymerization also influences the digestibility and prebiotic activity of inulin. For example, in the food industry, inulin with variable DP is required for the formulation of food products with specific properties $[6,9,29]$. Our study shows that the degree of polymerization of inulin and the content of sugars are related to 
the enzymatic activity of FEH as one of key enzymes in inulin metabolism. Therefore, choosing tuber harvesting time depending on FEH activity fluctuations is very important for the final recovery of inulin with desirable properties.

To sum up, the changes of fructan exohydrolase activity positively correlate with the changes of the content of total and short FOS. On the contrary, the negative correlation between FEH activity and DP of fructooligosaccharides was observed. Therefore, to extract inulin with higher DP for biotechnological purposes, the tubers of Jerusalem artichoke should be uprooted in autumn before the level of fructan exohydrolase reaches its maximum. At that time, tubers are also suitable for food as a resource of dietary fibers [30]. If short FOS are desirable, the tubers in late autumn or spring tubers overwintered in soil are suitable. Usually, short FOS are desirable for fermentation processes and ethanol production [5].

\section{Conclusions}

The study of fructan exohydrolase activity fluctuations in the tubers of Jerusalem artichoke revealed that the changes of carbohydrate content are related to FEH activity. It is a very important parameter determining the time of tubers harvesting and their quality for further application.

Supplementary Materials: The following are available online at http:/ /www.mdpi.com/2073-4395/8/9/184/s1, Figure S1: HPLC analysis of Albik tubers carbohydrates at the end of April (A), May (B) and July (C) , Figure S2: Seasonal fluctuations of kestose (A), nystose (B) and $\mathrm{GF}_{4}(\mathrm{C})$ in the tubers of Sauliai $(\bullet, \bigcirc)$, Albik $(\boldsymbol{\Lambda}, \Delta)$ and Rubik $(\mathbf{\square}, \square)$; spring tubers: $\bullet, \mathbf{\Lambda}, \mathbf{\square}$; summer and autumn tubers: $\bigcirc, \Delta, \square$, Figure S3: Seasonal fluctuations of sucrose determined by HPLC method in the tubers of Sauliai $(\bullet, \bigcirc)$, Albik $(\boldsymbol{\Lambda}, \Delta)$ and Rubik $(\mathbf{\square}, \square)$; spring tubers: $\bullet, \mathbf{\Lambda}, \mathbf{\square}$; summer and autumn tubers: $\bigcirc, \Delta, \square$, Figure S4: Seasonal fluctuations of glucose determined by HPLC method in the tubers of Sauliai $(\bullet, \bigcirc)$, Albik $(\boldsymbol{\Lambda}, \Delta)$ and Rubik $(\boldsymbol{\square}, \square)$; spring tubers: $\bullet, \boldsymbol{\Lambda}, \mathbf{\square}$; summer and autumn tubers: $\bigcirc$, $\Delta, \square$, Figure S5: Seasonal fluctuations of fructose determined by HPLC method in the tubers of Sauliai $(\bullet, \bigcirc)$, Albik $(\boldsymbol{\Lambda}, \Delta)$ and Rubik $(\mathbf{\square}, \square)$; spring tubers: $\bullet, \mathbf{\Lambda}, \mathbf{\square}$; summer and autumn tubers: $\bigcirc, \Delta, \square$.

Author Contributions: T.K. conducted the experiments and wrote the initial draft of the manuscript. J.S. designed the experiments and reviewed the manuscript.

Funding: This research received no external funding.

Acknowledgments: Thank you to Petras Tiknevicius for a regular supply of Jerusalem artichoke tubers.

Conflicts of Interest: The authors declare no conflict of interests.

\section{References}

1. Kays, S.J.; Nottingham, S.F. Biology and Chemistry of Jerusalem Artichoke: Helianthus tuberosus L., 1st ed.; CRC Press: Boca Raton, FL, USA, 2008; pp. 7-22.

2. Johansson, E.; Prade, T.; Angelidaki, I.; Svensson, S.E.; Newson, W.R.; Gunnarsson, I.B.; Hovmalm, H.P. Economically viable components from Jerusalem artichoke (Helianthus tuberosus L.) in a biorefinery concept. Int. J. Mol. Sci. 2015, 16, 8997-9016. [CrossRef] [PubMed]

3. Long, X.H.; Shao, H.B.; Liu, L.; Liu, Z.P. Jerusalem artichoke: A sustainable biomass feedstock for biorefinery. Renew. Sustain. Energy Rev. 2016, 54, 1382-1388. [CrossRef]

4. Yang, L.; He, Q.S.; Corscadden, K.; Udenigwe, C.C. The prospects of Jerusalem artichoke in functional food ingredients and bioenergy production. Biotechnol. Rep. 2015, 5, 77-88. [CrossRef] [PubMed]

5. Chi, Z.M.; Zhang, T.; Cao, T.S.; Liu, X.Y.; Cui, W.; Zhao, C.H. Biotechnological potential of inulin for bioprocesses. Bioresour. Technol. 2011, 102, 4295-4303. [CrossRef] [PubMed]

6. Mensink, M.; Frijlink, H.W.; van der Voort Maarschalk, K.; Hinrichs, W.L.J. Inulin, a flexible oligosaccharide: Review of its physicochemical characteristics. Carbohydr. Polym. 2015, 130, 405-419. [CrossRef] [PubMed]

7. Meyer, D.; Bayarri, S.; Tarrega, A.; Costell, E. Inulin as a texture modifier in dairy products. Food Hydrocoll. 2011, 25, 1881-1890. [CrossRef]

8. Segal, M.S.; Johnson, R.J. Is the fructose index more relevant with regards to cardiovascular disease than the glycemic index? Eur. J. Nutr. 2007, 46, 406-417. [CrossRef] [PubMed] 
9. Apolinario, A.C.; de Lima Damasceno, B.P.G.; de Macedo Beltrao, N.E.; Pessoa, A.; Converti, A.; da Silva, J.A. Inulin-type fructans: A review on different aspects of biochemical and pharmaceutical technology. Carbohydr. Polym. 2014, 101, 368-378. [CrossRef] [PubMed]

10. Edelman, J.; Jefford, T.G. The mechanism of fructosan metabolism in higher plants as exemplified in Helianthus tuberosus. New Phytol. 1968, 67, 517-531. [CrossRef]

11. Van den Ende, W.; de Coninck, B.; van Laere, A. Plant fructan exohydrolases: A role in signaling and defense? Trends Plant Sci. 2004, 9, 523-528. [CrossRef] [PubMed]

12. Gasperl, A.; Morvan-Bertrand, A.; Prud'homme, M.P.; van der Graaff, E.; Roitsch, T. A simple and fast kinetic assay for the determination of fructan exohydrolase activity in perennial ryegrass (Lolium perenne L.). Front. Plant Sci. 2015, 6, 1154. [CrossRef] [PubMed]

13. Clausen, M.R.; Bach, V.; Edeienbos, M.; Bertram, H.C. Metabolomics reveals drastic compositional changes during overwintering of Jerusalem artichoke (Helianthus tuberosus L.) tubers. J. Agric. Food Chem. 2012, 60, 9495-9501. [CrossRef] [PubMed]

14. Krivorotova, T.; Sereikaite, J. Seasonal changes of carbohydrates composition in the tubers of Jerusalem artichoke. Acta Physiol. Plant. 2014, 37, 79-83. [CrossRef]

15. Saengthongpinit, W.; Sajjaanantakul, T. Influence of harvest time and storage temperature on characteristics of inulin from Jerusalem artichoke. Postharvest Biol. Technol. 2005, 37, 93-100. [CrossRef]

16. Monti, A.; Amaducci, M.T.; Venturi, G. Growth response, leaf gas exchange and fructans accumulation of Jerusalem artichoke (Helianthus tuberosus L.) as affected by different water regimes. Eur. J. Agron. 2005, 23, 136-145. [CrossRef]

17. Kocsis, L.; Liebhard, P.; Praznik, W. Effect of seasonal changes on content and profile of soluble carbohydrates in tubers of different varieties of Jerusalem artichoke (Helianthus tuberosus L.). J. Agric. Food Chem. 2007, 55, 9401-9408. [CrossRef] [PubMed]

18. Slimestad, R.; Seljaasen, R.; Meijer, K.; Skar, S.L. Norwegian-grown Jerusalem artichoke (Helianthus tuberosus L.): Morphology and content of sugars and fructo-oligosaccharides in stems and tubers. J. Sci. Food Agric. 2010, 90, 956-964. [PubMed]

19. Bach, V.; Kidmose, U.; Bjørn, G.K.; Edelenbos, M. Effects of harvest time and variety on sensory quality and chemical composition of Jerusalem artichoke (Helianthus tuberosus) tubers. Food Chem. 2012, 133, 82-89. [CrossRef]

20. Muir, J.G.; Shepherd, S.J.; Rosella, O.; Rose, R.; Barrett, J.S.; Gibson, P.R. Fructan and free fructose content of common Australian vegetables and fruit. J. Agric. Food Chem. 2007, 55, 6619-6627. [CrossRef] [PubMed]

21. Marx, S.P.; Nosberger, J.; Frehner, M. Seasonal variation of fructan- $\beta$-fructosidase (FEH) activity and characterization of a $\beta-(2-1)$ linkage specific FEH from tubers of Jerusalem artichoke (Helianthus tuberosus). New Phytol. 1997, 135, 267-277. [CrossRef]

22. Krivorotova, T.; Sereikaite, J. Determination of fructan exohydrolase activity in the crude extracts of plants. Electron. J. Biotechnol. 2014, 17, 329-333. [CrossRef]

23. Kusch, U.; Harms, K.; Rausch, T.; Greiner, S. Inhibitors of plant invertases do not affect the structurally related enzymes of fructan metabolism. New Phytol. 2009, 181, 601-612. [CrossRef] [PubMed]

24. Van den Ende, W.; Lammens, W.; Van Laere, A.; Schroeven, L.; Le Roy, K. Donor and acceptor substrate selectivity among plant glycoside hydrolase family 32 enzymes. FEBS J. 2009, 276, 5788-5798. [CrossRef] [PubMed]

25. Hu, H.; Liang, M.; Xu, L.; Li, H.; Zhang, H.; Kang, J.; Zhao, Q.; Zhao, H. Cloning and functional characterization of two abiotic stress-responsive Jerusalem artichoke (Helianthus tuberosus) fructan 1-exohydrolases (1-FEHs). Plant Mol. Biol. 2015, 87, 81-98.

26. Itaya, N.M.; Asega, A.F.; Carvalho, M.A.M.; Figueiredo-Ribeiro, R.; de Cassia, L. Hydrolase and fructosyltranferase activities implicated in the accumulation of different chain size fructans in three Asteraceae species. Plant Physiol. Biochem. 2007, 45, 647-656. [CrossRef] [PubMed]

27. Baldini, M.; Danuso, F.; Turi, M.; Vannozi, G.P. Evaluation of new clones of Jerusalem artichoke (Helianthus tuberosus L.) for inulin and sugar yield from stalks and tubers. Ind. Crops Prod. 2004, 19, 25-40. [CrossRef]

28. Lingyun, W.; Jianhua, W.; Xiaodong, Z.; Da, T.; Yalin, Y.; Chenggang, C.; Tianhua, F.; Fan, Z. Studies on the extraction technical conditions of inulin from Jerusalem artichoke tubers. J. Food Eng. 2007, 79, 1087-1093. [CrossRef] 
29. Flores, A.C.; Morlett, J.A.; Rodriguez, R. Inulin potential for enzymatic obtaining of prebiotic oligosaccharides. Crit. Rev. Food Sci. Nutr. 2016, 56, 1893-1902. [CrossRef] [PubMed]

30. Delgado, G.T.C.; da Silva Cunha Tamashiro, W.M. Role of prebiotics in regulation of microbiota and prevention of obesity. Food Res. Int. 2018, 113, 183-188. [CrossRef] [PubMed]

(c) 2018 by the authors. Licensee MDPI, Basel, Switzerland. This article is an open access article distributed under the terms and conditions of the Creative Commons Attribution (CC BY) license (http://creativecommons.org/licenses/by/4.0/). 